\title{
Alpha Defensins Genes and Vulvovaginal Candidiasis: A Study of Cases
}

\author{
Humberto F. Boatto1,2, Elaine C. Francisco², João P. Kleine³, Ismael D. Silva ${ }^{3,4}$, \\ Manoel J. B. C. Girão ${ }^{3}$, Alexandre P. Machado ${ }^{5 *}$, Olga Fischman ${ }^{2}$ \\ ${ }^{1}$ Medical Clinic Department, Medical Faculty, University of Mogi das Cruzes, \\ Mogi das Cruzes, Brazil \\ ${ }^{2}$ Mycology Laboratory, Microbiolology, Immunology and Parasitology Department, \\ Federal University of São Paulo, São Paulo, Brazil \\ ${ }^{3}$ Gynecology Department, Federal University of São Paulo, São Paulo, Brazil \\ ${ }^{4}$ Molecular Oncology Research Center, Barretos Cancer Hospital, Pio XII Foundation, Barretos, Brazil \\ ${ }^{5}$ Microbiology Laboratory of Health Basic Sciences Department, Medical Faculty, Federal University of Mato \\ Grosso, Cuiabá, Brazil \\ Email: alepaulo@hotmail.com
}

Received 14 July 2015; accepted 22 August 2015; published 26 August 2015

Copyright (C) 2015 by authors and Scientific Research Publishing Inc.

This work is licensed under the Creative Commons Attribution International License (CC BY). http://creativecommons.org/licenses/by/4.0/

(c) (i) Open Access

\section{Abstract}

Objective: To evaluate the alpha-defensin ( $\alpha$-DF) genes polymorphism in women with vulvovaginal candidiasis and recurrence. Methods: This observational study included clinical vaginal secretion samples collected over four years from 88 women, ranging in age from 18 to 65 years, from medical centers of São Paulo and Mogi das Cruzes, Brazil. Thirty-six of these women were asymptomatic (control group) and 52 presented clinical condition compatible with vulvovaginitis (38 primary or episodic as non-recurrent forms, and 14 recurrent vulvovaginal candidiasis). A portion of each sample was plated on Sabouraud dextrose agar with chloramphenicol and grown on CHROMagar Candida for presumptive characterization. The identification of the species was obtained by sequencing of the ITS1 region of rDNA. $\alpha$-DF genes were amplified for subsequent evaluation of polymorphisms by endonuclease restriction assay. Results: From 88 samples were isolated 60 Candida albicans and 28 non-albicans Candida spp. Resistant $C$. albicans strains and non-albicans Candida spp. were more prevalent in recurrence. In all groups, the number of resistant non-albicans Candida spp. was most high than susceptible strains. $\alpha$-DF1, $\alpha$-DF3 and $\alpha$-DF1/ $\alpha$-DF3 genotypes were found in 32 (36.4\%), 17 (19.3\%), 6 (6.8\%) vaginal samples, respectively. About 33 samples were not amplified. Recurrence and severe disease were more observed in homozygous population. Conclusions: Non-albicans Candida spp. and homozygotic $\alpha$-DF genotipes ( $\alpha$-DF1 and $\alpha$-DF3) were more related with severe clinical signs and recurrence. Further studies about vulvovaginal candidiasis and $\alpha$-DF genes are necessary to access the more comprehen-

${ }^{*}$ Corresponding author.

How to cite this paper: Boatto, H.F., Francisco, E.C., Kleine, J.P., Silva, I.D., Girão, M.J.B.C., Machado, A.P. and Fichman, O. (2015) Alpha Defensins Genes and Vulvovaginal Candidiasis: A Study of Cases. Open Journal of Obstetrics and Gynecology, 5, 487-493. http://dx.doi.org/10.4236/ojog.2015.59071 
sive role of defensins in clinical manifestations.

Keywords Alpha-Defensin Genes, Candida albicans, Non-Albicans Candida, Vulvovaginal Candidiasis,
Recurrent Vulvovaginal Candidiasis

\section{Introduction}

Vulvovaginitis (VV) is the main reason for a third of all gynecological medical visits, and the most common gynecologic disease in pregnant or non-pregnant women [1]. Candida spp. is the second most important agent in these infections [2]-[4].

Candida albicans is responsible for $80 \%$ - 92\% of all vulvovaginal candidiasis cases (VVC) [5]-[7]. However, the frequency of other species as causative agents for this disease is increasing, particularly those with different susceptibility profiles to antifungal agents, possibly because of the indiscriminate use or misuse of these drugs, which may result in recurrent infections [8]-[11].

Recurrent vulvovaginal candidiasis (RVVC) is defined by the occurrence of three or more VVC recorded episodes, with clinical diagnosis and culture confirmation, in the course of one year [12] [13]. Chronic stress [14], changes in hormone levels [12], use of oral contraceptives [15], use of intrauterine devices, and virulence factors of the infectious agents have been associated with the development of the disease [16] [17].

Defensins (DF) are important antimicrobial polypeptides that act in host defense [18] [19]. Leukocytes and epithelial cells expressed DF as component of innate immunity [18] [20]. DF polymorphisms may be involved in susceptibility to infection by Candida spp. or entrainment of the agent [21] [22].

Fluids from patients with genital infections show high levels of alpha-DF ( $\alpha$-DF) modulating the innate immunity expressed in the mucosal surface. In addition to the presence of polymorphisms in the $\alpha$-DF gene, other factors such as the age, hormonal influence, cervicovaginal mucus, and innate immune defense can be related to the recurrence of VVC [23]-[29].

The goal of this study was to evaluate the presence of $\alpha$-DF genes in women with or without clinical condition of candidiasis.

\section{Materials and Methods}

In two medical centers to São Paulo and one of Mogi das Cruzes, Brazil, 88 women, between 18 and 65 years old, were selected to participate in the study; 52 presented VVC (38 cases of non-recurrent and 14 of recurrent vaginitis) and 36 were asymptomatic (control group). Each patient with gynecological complaints was subjected to a thorough clinical examination. The vaginitis cases were classified as primary (one single episode), repeated (2 episodes/year), and recurrent ( $\geq 3$ episodes/year). The exclusion criteria for the study were pregnancy, diabetes mellitus, HIV infection, immune-suppression, treatment with corticosteroids, antimicrobials, and hormone replacement, and use of an intrauterine device (IUD), vaginal douches, or spermicidal products. Samples of vaginal secretion were collected from all participants on the outside surface of the cervix and posterior vaginal fornix. Patients with vaginitis and clinical manifestations of leukorrhea, pruritus, dysuria, edema, erythema, burning and vulvar pain were examined and their signs and symptoms were recorded in individual form and received arbitrated scores according to the following scale and clinical presentation of the two studied groups: $0=$ absent, 1 = mild, 2 = moderate, 3 = severe. They were considered patients with mild clinical frames those obtained 0 - 6 points, moderate 7 to 13 points, and severe more than 13 points. For the treatments of VVC patients was employed weekly $150 \mathrm{mg}$ of oral fluconazole single-dose, nystatin vaginal cream $2 \%$ or a combination of them. To refractory and recurrence cases, these treatments were carried for prolonged periods generally superior to 3 months. Institutional review board approval was obtained from Ethics Committee of the Federal University of São Paulo $n^{\circ} 1719 / 05$, and that the participants gave informed consent.

All samples were plated on Sabouraud Dextrose Agar and CHROMagar Candida ${ }^{\circledR}$ (Difco, USA), incubated at $37^{\circ} \mathrm{C}$ for 48 hours. The phenotypic identification was accessed by micro- and macro-morphological evaluations and biochemical profiling. The molecular identification was performed by sequencing the ITS1 region of rDNA. 
Azole-resistance or susceptible profile of yeasts strains was evaluated by Etest (AB BIODISK, Solna, Sweden). Ketoconazole and fluconazole strips were used for direct antifungal susceptibility testing.

DNA extraction from the vaginal samples was performed with the Amersham-Pharmacia GFX ${ }^{\circledR}$ kit, and according to the manufacturer's instructions. Polymorphisms were assessed in PCR fragments of $\alpha$-DF genes amplified with the primers DEF F (5'-CAG CGG ACA TCC CAG AAG TGG-3') and DEF R (5'-GCG TTT TGG TAC GTG TAT CC-3') according to [30]. The beta-globin gene was used as the PCR reaction control and amplified using the primers GH20 (5'-GAA GAG CCA AGG ACA GGT AC-3') and PC04 (5'-CTT CAA CAT CCA CGT TCA CC-3'). PCR amplified fragments were digested with the restriction enzyme HAE III (New England Biolabs Inc., Beverly, MA) for 4 hours at $37^{\circ} \mathrm{C}$ in a water bath, to assess the presence of $\alpha$-DF 1 and $\alpha$ DF 3.

\section{Results}

The homozygous and heterozygous patterns of the $\alpha$-DF genes, after digestion with HAE III, are presented in Figure 1. The presence of the $\alpha$-DF1 polymorphic allele was evidenced by two fragments with 650 bp and 300 bp, after digestion with HAE III. Heterozygous patients ( $\alpha$-DF1/ $\alpha$-DF3 genotype), carriers of one wild type allele and one polymorphic allele, showed a restriction pattern with three fragments, of 950, 650, and $300 \mathrm{bp}$. The wild type homozygous genotype (of rare incidence) showed only one fragment with $950 \mathrm{bp}$. Lanes 01, 03, 04, and 06 show the polymorphic homozygous pattern that represents the $\alpha$-DF1 genotype. Lanes 02,05 , and 07 show the heterozygous pattern that represents the $\alpha$-DF1/ $\alpha$-DF3 genotype. Lane 09 shows the wild type pattern that represents the $\alpha$-DF3 genotype. Lane 08 shows negative $\alpha$-DF gene PCR amplification.

The identification of the species found in the control group and patients with VVC and recurrent forms is shown in Table 1. Candida albicans was identified in 60 out of 88 isolates. High number of resistant species was observed in group of non-albicans Candida spp. (57.1\%), while C. albicans resistance rate was $20 \%$. Resistant species were more associated to recurrence (RVVC). In this study, we also observed that the treatment failure of VVC refractory or relapsed was mostly related with the decreased susceptibility to antifungal agents and the presence of fluconazole-resistant Candida isolates.

A high percentage of homozygous polymorphisms in $\alpha$-DF genes were observed in 10 out of 14 patients with RVVC (71.4\%) compared to the non-recurrent (5 out of 38\% - 13.2\%) or control groups (8 out of 36\% - 22.2\%). In cases of non-RVVC we observed clinical manifestations predominantly mild or moderate in $37(90 \%)$ patients, severe symptoms and signs in only one woman (3\%) (Table 2). Vaginal discharge, pruritus, and erythema were the main manifestations of VVC non-recurrent group (78.9\%), being edema observed in 11 cases (28.9\%). Seven patients $(18.4 \%)$ presented only mild or moderate pruritus, edema, and erythema. All RVVC cases had vaginal discharge, pruritus, erythema, edema, vulvovaginal burning sensation and pain. Five RVVC patients (36\%) had severe symptoms (verified more in homozygotes). The presence of heterozygosis or homozygosis in $\alpha$-DF genes may also be associated to the occurrence of C. albicans compared to non-albicans Candida spp. In

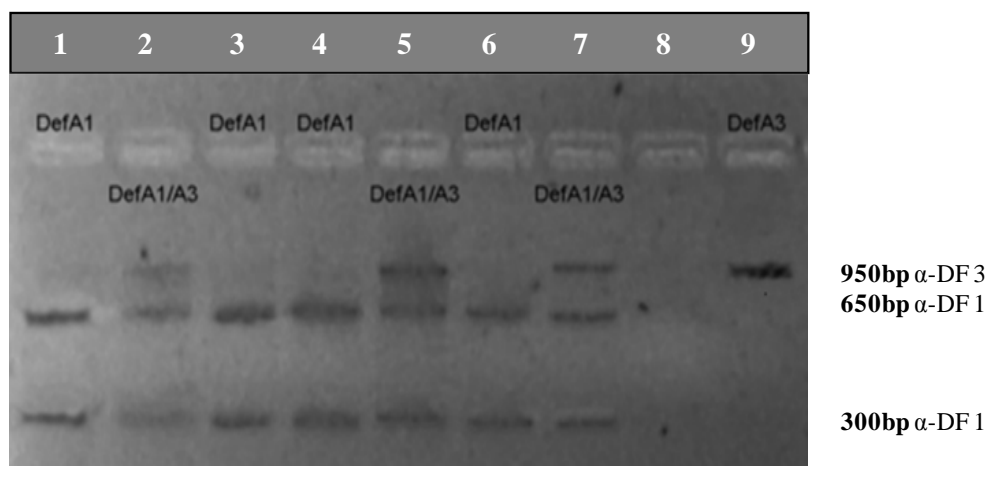

Figure 1. Agarose gel electrophoresis of the alpha-defensin ( $\alpha$-DF) genes PCR fragments digested by endonuclease HAE III. $\alpha$-DF1 restriction patterns with 650 and 300 bp (DefA1, lanes 1, 3, 4, and 6). $\alpha$-DF3 fragment with 950 bp (DefA3, lane 9). $\alpha$-DF1/ $\alpha$-DF3 heterozygous patterns with 950, 650 and 300 bp (DefA1/A3, lanes 2, 3 and 7). No PCR-product after enzymatic restriction (lane 8). 
Table 1. Profile of Candida isolates from three group samples.

\begin{tabular}{cccccc}
\hline Groups & \multicolumn{2}{c}{ C. albicans } & \multicolumn{2}{c}{ Non-albicans } & Total \\
\hline Asymptomatic & $\mathrm{S}$ & $\mathrm{R}$ & $\mathrm{S}$ & $\mathrm{R}$ & \\
VVC & 20 & 5 & 5 & 6 & 36 \\
RVVC & 27 & 2 & 6 & 3 & 38 \\
Total & 1 & 5 & 1 & 7 & 14 \\
\hline
\end{tabular}

S: susceptible, R: resistant, VVC: vulvovaginal candidiasis, RVVC: recurrent vulvovaginal candidiasis.

Table 2. Alpha-defensin genes according clinical presentations of the groups.

\begin{tabular}{cccc}
\hline$\alpha$ DF-genes & Asymptomatic & Non-RVVC & RVVC \\
$\alpha$-DF1 & 4 & L (3), M (1) & M (5), S (4) \\
$\alpha$-DF3 & 4 & L (1) & S (1) \\
$\alpha$-DF1/ $\alpha$-DF3 & 14 & L (4), M (10) & M (4) \\
No PCR-product & 14 & L (3), M (15), S (1) & \\
Total & 36 & L (11), M (26), S (1) & M (9), S (5) \\
\hline
\end{tabular}

L: mild; M: moderate; S: severe.

heterozygosis, C. albicans and non-albicans Candida spp. rate were 28 (50.9\%) and 4 (7.3\%), while in homozygosis were 10 (18.2\%) and 13 (23.6\%), respectively.

\section{Discussion}

Defensins, important peptides found in polymorphonuclear and epithelial cells, participate in the innate immune response by acting as critical immune adjuvants against pathogenic microorganisms before the acquired immune response is mounted [31]-[35]. In addition to inducing cytokine production, which ensures activity against Gram-positive and Gram-negative bacteria, fungi, and viruses, including non-enveloped viruses such as HIV, $\alpha$-DF immunostimulates T cells, monocytes, and immature dendritic cells [19] [31] [36] [37].

Candida colonization can induce a high expression of defensins [38] [39]. Neutrophils release $\alpha$-DF1 to periand extracellular matrix as a important factor against Candida [40]. The presence of polymorphisms can act on host-parasite relationships [12] [28] [29]. We observed more high frequencies of $\alpha$-DF homozygote genotypes in the group of recurrent patients than in the non-recurrent and control groups, which suggest that the polymorphism might have an important role in VVC relapses. Although the presence of polymorphisms in $\alpha$-DF genes, which may be considered as a relevant factor for the maintenance of VVC recurrent, other factors such as the hormonal influence, innate immune defense, microbiota, physiological regulation and the species involved in the process should be taken into consideration.

Candida albicans and non-albicans Candida spp. have become more resistant to azoles in the last decades, whereas nystatin has shown good results in vitro and in vivo, including against the fluconazole-resistant yeast strains [41] [42]. Clinical and mycological cure over $90 \%$ of cases were provide after short treatments with oral azoles and/or nystatin topical. Oral fluconazole dose (150 mg once-weekly) has been recommended as standard therapy for VVC and recurrence, showing high therapeutic efficacy [43] [44]. Two oral doses of fluconazole $150 \mathrm{mg}$ regimen were effective in the treatment of severe VVC [45]. However, prolonged treatment with triazole and polyenes antifungals, during periods of time between 3 to 12 months may be necessary particularly in RCVV cases [42] [46] [47].

\section{Conclusion}

Our results suggest that the $\alpha$-DF polymorphisms may be related to the recurrence of VVC and severity of signs 
and symptoms especially in homozygotic females. Further investigations on the $\alpha$-DF genes polymorphism are necessary to better elucidate their rule in pathophysiology of VVC and RVVC, and the possible relationship with symptomatology and therapeutics.

\section{Conflict of Interest}

The authors did not report any potential conflicts of interest. The authors alone are responsible for the content and writing of the paper.

\section{Acknowledgements}

This study was financially supported by the Brazilian National Council for Scientific and Technological Development (CNPq, Brazil). We thank to Claudia R. C. Porto for support in laboratory tests.

\section{References}

[1] Alvares, C.A., Svidzinski, T.I.E. and Consolaro, M.E.L. (2007) Vulvovaginal Candidiasis: Susceptibility Factors of the Host and Virulence of the Yeasts. Jornal Brasileiro de Patologia e Medicina Laboratorial, 43, 319-327. http://dx.doi.org/10.1590/S1676-24442007000500004

[2] Rosa M.I. and Rumel, D. (2004) Fatores associados a candidíase vulvovaginal: Estudo exploratório. Revista Brasileira de Ginecologia e Obstetrícia, 26, 65-70. http://dx.doi.org/10.1590/S0100-72032004000100010

[3] Rylander, E., Berglund, A.L., Krassny, C. and Petrini, B. (2004) Vulvovaginal Candida in a Young Sexually Active Population: Prevalence and Association with Oro-Genital Sex and Frequent Pain at Intercourse. Sexually Transmitted Infections, 80, 54-57. http://dx.doi.org/10.1136/sti.2003.004192

[4] Caiyan, X., Weiyuan, Z., Minghui, W. and Songwen, Z. (2012) Prevalence and Risk Factors of Lower Genital Tract Infections among Women in Beijing, China. The Journal of Obstetrics and Gynaecology Research, 38, 310-315.

[5] Corrêa, P.R., David, P.R.S., Peres, N.P., Cunha, K.C. and Almeida, M.T.G. (2009) Phenotypic Characterization of Yeasts Isolated from the Vaginal Mucosa in Adult Women. Revista Brasileira de Ginecologia e Obstetrícia, 31, 177181. http://dx.doi.org/10.1590/S0100-72032009000400004

[6] Gunther, L.S., Martins, H.P., Gimenes, F., Abreu, A.L., Consolaro, M.E. and Svidzinski, T.I. (2014) Prevalence of Candida albicans and Non-Albicans Isolates from Vaginal Secretions: Comparative Evaluation of Colonization, Vaginal Candidiasis and Recurrent Vaginal Candidiasis in Diabetic and Non-Diabetic Women. São Paulo Medical Journal, 132, 116-120. http://dx.doi.org/10.1590/1516-3180.2014.1322640

[7] Mnichowska-Polanowskai, M., Wojciechowska-Koszko, I., Klimowicz, B., et al. (2013) Endogenous or Exogenous Origin of Vaginal Candidiasis in Polish women? Polish Journal of Microbiology, 82, 532-543.

[8] Corsello, S. (2003) An Epidemiological Survey of Vulvovaginal Candidiasis in Italy. European Journal of Obstetrics \& Gynecology and Reproductive Biology, 110, 66-72. http://dx.doi.org/10.1016/S0301-2115(03)00096-4

[9] Douglas, L.J. (2003) Candida Biofilms and Their Role in Infection. Trends in Microbiology, 11, 30-36. http://dx.doi.org/10.1016/S0966-842X(02)00002-1

[10] Pádua, R.A.F., Guilhermetti, E. and Svidzinski, T.I.E. (2003) In Vitro Activity of Antifungal Agents on Yeasts Isolated from Vaginal Secretion. Acta Scientiarum, Health Sciences, 25, 51-54.

[11] Ferrazza, M.H.S.H., Maluf, M.L.F., Consolaro, M.E.L., Shinobu, C.S., Svidzinski, T.I.E. and Batista, M.R. (2005) Characterization of Yeasts Isolated from the Vagina and Their Association with Vulvovaginal Candidiasis in Two Cities in Southern Brazil. Revista Brasileira de Ginecologia e Obstetrícia, 27, 58-63. http://dx.doi.org/10.1590/S0100-72032005000200003

[12] Spacek, J., Buchta, V., Jilek, P. and Förstl, M. (2007) Clinical Aspects and Luteal Phase Assesment in Patients with Recurrent Vulvovaginal Candidiasis. European Journal of Obstetrics \& Gynecology and Reproductive Biology, 48, 165171.

[13] Hong, E., Dixit, S., Fidel, P.L., Bradford, J. and Fischer, G. (2014) Vulvovaginal Candidiasis as a Chronic Disease: Diagnostic Criteria and Definition. Journal of Lower Genital Tract Disease, 18, 31-38. http://dx.doi.org/10.1097/LGT.0b013e318287aced

[14] Ehrström, S.M., Kornfeld, D., Thuresson, J. and Rylander, E. (2005) Signs of Chronic Stress in Women with Recurrent Candida Vulvovaginitis. American Journal of Obstetrics \& Gynecology, 193, 1376-1381. http://dx.doi.org/10.1016/j.ajog.2005.03.068

[15] Fleming, D.C. (2003) Hormonal Contraception Can Suppress Natural Antimicrobial Gene Transcription in Human Endometrium. Fertility and Sterility, 79, 856-863. http://dx.doi.org/10.1016/S0015-0282(02)04930-0 
[16] Ziarrusta, G.B. (2002) Vulvovaginitis Candidiásica. Revista Iberoamericana de Micología, 19, 22-24.

[17] Barbedo, L.S. and Sgarbi, D.B.G. (2010) Candidíase. DST. Jornal Brasileiro de Doenças Sexualmente Transmissíveis, 22, 22-38.

[18] Ding, J., Chou, Y.Y. and Chang, T.L. (2009) Defensins in Viral Infections. Journal of Innate Immunity, 1, $413-420$. http://dx.doi.org/10.1159/000226256

[19] Vega, A., Ventura, I. and Chamorro, C. (2011) Neutrophil Defensins: Their Possible Role in Allergic Asthma. Journal of Investigational Allergology and Clinical Immunology, 21, 38-43.

[20] Suarez-Carmona, M., Hubert, P., Delvenne, P. and Herfs, M. (2015) Defensins: “Simple” Antimicrobial Peptides or Broad-Spectrum Molecules? Cytokine \& Growth Factor Reviews, 26, 361-70. http://dx.doi.org/10.1016/j.cytogfr.2014.12.005

[21] Smith, J.G. and Nemerow, G.R. (2008) Mechanisms of Adenovirus Neutralization by Human Alpha Defensins. Cell Host Microbe, 3, 11-19. http://dx.doi.org/10.1016/j.chom.2007.12.001

[22] Wehkamp, J., Wang, G., Kübler, I., et al. (2007) The Paneth Cell Alpha-Defensin Deficiency of Ileal Crohn’s Disease Is Linked to Wnt/Tcf-4. The Journal of Immunology, 179, 3109-3118. http://dx.doi.org/10.4049/jimmunol.179.5.3109

[23] Jurevic, R.J., Bai, M., Chadwick, R.B., White, T.C. and Dale, B.A. (2003) Single-Nucleotide Polymorphisms (SNPs) in Human Beta-Defensin 1: High-Throughput SNP Assays and Association with Candida Carriage in Type 1 Diabetics and Nondiabetics Controls. Journal of Clinical Microbiology, 41, 90-96. http://dx.doi.org/10.1128/JCM.41.1.90-96.2003

[24] Vylkova, S., Nayyar, N., Li, W. and Edgerton, M. (2007) Human Beta-Defensins Kill Candida albicans in an EnergyDependent and Salt-Sensitive Manner without Causing Menbrane Disruption. Antimicrobial Agents and Chemotherapy, 51, 154-161. http://dx.doi.org/10.1128/AAC.00478-06

[25] Fan, S.R., Liu, X.P. and Liao, Q.P. (2008) Human Defensins and Cytokines in Vaginal Lavage Fluid of Women with Bacterial Vaginosis. International Journal of Gynecology \& Obstetrics, 103, 50-54. http://dx.doi.org/10.1016/j.ijgo.2008.05.020

[26] Krishnakumari, V., Rangaraj, N. and Nagaraj, R. (2009) Antifungal Activities of Human Beta Defensins HBD-1 to HBD-3 and Their c-Terminal Analogs Phd1 to Phd3. Antimicrobial Agents and Chemotherapy, 53, 256-260. http://dx.doi.org/10.1128/AAC.00470-08

[27] Levinson, P., Kaul, R., Kimani, J., et al. (2009) Levels of Innate Immune Factors in Genital Fluids: Association of Alpha Defensins and LL-37 with Genital Infections and Increased HIV Acquisition. AIDS, 23, 309-317. http://dx.doi.org/10.1097/QAD.0b013e328321809c

[28] Feuerschuette, O.H.M., Silveira, S.K., Feuerschuette, I., Correa, T., Grando, L. and Trepani, Q. (2010) Recurrent Vaginal Candidiasis: Clinical Management. Femina, 38, 31-36. http://files.bvs.br/upload/S/0100-7254/2010/v38n1/a005.pdf

[29] Corrales-Garcia, L.L., Possani, L.D. and Corzo, G. (2011) Expression Systems of Human $\beta$-Defensins: Vectors, Purification and Biological Activities. Amino Acids, 40, 5-13. http://dx.doi.org/10.1007/s00726-010-0493-7

[30] Wallace, M.A., He, J.Q., Burkett, K.M., et al. (2006) Contribution of Alpha and Beta Defensins to Lung Function Decline and Infection in Smokers: An Association Study. Respiratory Research, 7, 76. http://dx.doi.org/10.1186/1465-9921-7-76

[31] Ganz, T. (1999) Defensins and Host Defense. Science, 286, 420-421. http://dx.doi.org/10.1126/science.286.5439.420

[32] Hackett, C.J. (2003) Innate Immune Activation as a Broad-Spectrum Biodefense Strategy: Prospects and Research Challenges. Journal of Allergy and Clinical Immunology, 112, 686-694. http://dx.doi.org/10.1016/S0091-6749(03)02025-6

[33] Castañeda-Casimiro, J., Ortega-Roque, J.A., Venegas-Medina, A.M., et al. (2009) Péptidos antimicrobianos: Péptidos con múltiples funciones. Alergia, Asma e Inmunología Pediátricas, 18, 16-29. http://www.medigraphic.com/pdfs/alergia/al-2009/al091d.pdf

[34] Ahn, J.K., Cha, H.S., Lee, J., Jeon, C.H. and Koh, E.M. (2012) Correlation of DEFA1 Gene Copy Number Variation with Intestinal Involvement in Behcet’s Disease. Journal of Korean Medical Science, 27, 107-109. http://dx.doi.org/10.3346/jkms.2012.27.1.107

[35] Glenthøj, A., Glenthøj, A.J. and Borregaard, N. (2013) ProHNPs Are the Principal $\alpha$-Defensins of Human Plasma of Human Plasma. European Journal of Clinical Investigation, 43, 836-843. http://dx.doi.org/10.1111/eci.12114

[36] Bastian, A. and Schafer, H (2001) Human Alpha-Defensin 1 (HNP-1) Inhibits Adenoviral Infection in Vitro. Regulatory Peptides, 101, 157-161. http://dx.doi.org/10.1016/S0167-0115(01)00282-8

[37] Lehrer, R.I. and Ganz, T. (2002) Defensins of Vertebrate Animals. Current Opinion in Immunology, 14, 96-102. http://dx.doi.org/10.1016/S0952-7915(01)00303-X 
[38] Kiehne, K., Brunke, G., Meyer, D., Harder, J. and Herzig. K.H. (2005) Oesophageal Defensing Expression during Candida Infection and Reflux Disease. Scandinavian Journal of Gastroenterology, 40, 501-507. http://dx.doi.org/10.1080/00365520510015386

[39] Vento, G., Lio, A., Tirone, C., et al. (2013) Association of High Levels of $\alpha$-Defensins and S100A Proteins with Candida Mannan Detection in Bronchoalveolar Lavage Fluid of Preterm Neonates. Pediatric Research, 74, 19-25. http://dx.doi.org/10.1038/pr.2013.60

[40] Raj, P.A., Antonyraj, K.J. and Karunakaran, T. (2000) Large-Scale Synthesis and Functional Elements for the Antimicrobial Activity of Defensins. The Biochemical Journal, 347, 633-641. http://dx.doi.org/10.1042/0264-6021:3470633

[41] Fan, S., Liu, X., Wu, C., Xu, L. and Li, J. (2015) Vaginal Nystatin versus Oral Fluconazole for the Treatment for Recurrent Vulvovaginal Candidiasis. Mycopathologia, 179, 95-101. http://dx.doi.org/10.1007/s11046-014-9827-4

[42] Fan, S.R. and Liu, X.P. (2011) In Vitro Fluconazole and Nystatin Susceptibility and Clinical Outcome in Complicated Vulvovaginal Candidosis. Mycoses, 54, 501-505. http://dx.doi.org/10.1111/j.1439-0507.2010.01887.x

[43] Martins, H.P., da Silva, M.C., Paiva, L.C., Svidzinski, T.I. and Consolaro, M.E. (2012) Efficacy of Fluconazole and Nystatin in the Treatment of Vaginal Candida Species. Acta Dermato-Venereologica, 92, 78-82.

[44] Mikamo, H., Matsumizu, M., Nakazuru, Y., Okayama, A. and Nagashima, M. (2015) Efficacy and Safety of a Single Oral $150 \mathrm{mg}$ Dose of Fluconazole for the Treatment of Vulvovaginal Candidiasis in Japan. Journal of Infection and Chemotherapy, 21, 520-526. http://dx.doi.org/10.1016/j.jiac.2015.03.011

[45] Fan, S., Liu, X. and Liang, Y. (2015) Miconazole Nitrate Vaginal Suppository 1200 mg versus Oral Fluconazole 150 $\mathrm{mg}$ in Treating Severe Vulvovaginal Candidiasis. Gynecologic and Obstetric Investigation, $\mathbf{8 0}$. http://dx.doi.org/10.1159/000371759

[46] Sobel, J.D. (2015) Recurrent Vulvovaginal Candidiasis. American Journal of Obstetrics \& Gynecology. http://dx.doi.org/10.1016/j.ajog.2015.06.067

[47] Mendling, W. (2015) Guideline: Vulvovaginal Candidosis (AWMF 015/072), S2k (Excluding Chronic Mucocutaneous Candidosis). Mycoses, 58, 1-15. http://dx.doi.org/10.1111/myc.12292 